EPiC Series in Education Science
Volume 3, 2020, Pages 178-187
Proceedings of the MIT LINC 2019 Conference

\title{
The Role and Effectiveness of Coaching in Increasing Self-Efficacy and Employability Efforts of Higher Education Students
}

\author{
Joanna Molyn \\ University of Greenwich, London, U.K. \\ J.Molyn@greenwich.ac.uk
}

\begin{abstract}
In this quasi-experimental longitudinal mixed-methods study we examined the link between coaching, self-efficacy and the employability efforts of students from a widening participation university (a university which aims to offer education to students regardless of their socioeconomic status, income, age, disability or ethnicity) in the United Kingdom. We investigated effectiveness of coaching used as an employability-enhancing tool.
\end{abstract}

We also examined what aspects of coaching relationship are most effective in changing students' career self-efficacy beliefs, outcome expectations and employability efforts.The study also explored the impact of gender, ethnicity, perceived social support, socioeconomic status, cultural influences and gender role models on students' selfefficacy beliefs, outcome expectations and their employability efforts.

We analyzed the above factors in the context of the changing role of Higher Education. Our study explored a need for the widening participation universities in the United Kingdom to address the issues of gender, ethnicity, perceived social support, socioeconomic status, cultural influences and gender role models in their employability strategy.

We used Social Cognitive Career Theory (SCCT) as the main theoretical framework as SCCT recognizes the links between psychological and social effects of gender and ethnicity, the social-cultural environment and career opportunity structures. We positioned coaching as a learning experience within the SCCT framework. 


\section{Introduction}

Higher Education institutions in the United Kingdom have been facing increasing economic, political and environmental pressures [13][14][33][54]. The topic of the role of Higher Education has been highly polarizing as some argue that its purpose is the quest of knowledge whereas others say its role is to provide skilled graduates to society [18][10]. The UK government's 2010-2011 legislative program resulted in the removal of public subsidies from universities, in higher tuition fees and started the marketisation of Higher Education [13]. These developments also initiated the rise of McKinseyism thinking in Higher Education - what cannot be measured has no value [54] - amongst policy makers and academic managers [11].

Increasingly, universities are promoting the view that the role of Higher Education is to provide students with the corporate job at the end of their studies [54]. Subsequently, universities - and widening-participation universities in particular - are being transformed into the providers of narrow, utilitarian vocational training serving the corporate business environment [54], ultimately producing universities without debates or political activity [11] that resemble corporate institutions and that exude "numbing brainlessness, the same suffocating absence of thought and imagination, the same absoluteness about the unquestioning conformity. So drained of intellect, culture, and politics are they that many of these places are the very negation of 'universities'." [11:28].

As a result, the role of Higher Education is shifting from being a facilitator of knowledge to becoming a provider of vocational training to socially disadvantaged students occupying lower tiers of the league tables [13]. Widening-participation universities cannot afford to cater for students' individual needs and instead have to offer what is required of mass market education, hence, being forced to act as corporate entities and to promote market-driven ideologies [13], including pseudo-practical vocationalism, standardisation, managerialism, auditing and policing of students and lecturers [54]. In contrast, Russell Group universities - research universities in the UK - that attract most research funding are able to provide "niche offerings" (p.2) to their students [13][40].

These issues are further compounded by the importance of the league tables. Preoccupation with academic rankings not only leads to a materialistic mindset in academia [46] but it also affects students' prospective graduate employment [7][40][51]. The top of the league tables is occupied by the Russell Group whose students mostly come from privileged, highly socially selected backgrounds [40][51]. As a result, the choices of vocational professions and employability opportunities offered to students in the United Kingdom differ vastly: students from the Russell Group universities occupy the top positions in the well-paid professions whereas students from widening participation universities study more vocational courses and struggle to find graduate employment [7][40][51]. Moreover, students recruited under a widening participation agenda often have less access to social capital and to professional role models [24][49].

Furthermore, the recent review of employability literature [18:7] emphasizes the Higher Education Academy's call to support "students to increase their confidence, self-belief and self-efficacy through their studies.". A number of studies have confirmed that coaching has a significant positive effect on self-efficacy [27]. However, despite coaching being recognised as an effective learning tool [16], coaching has not been used to any significant extent with students - or researched for its effectiveness - in Higher Education institutions. 
Hereafter, we argue that there is a need for widening-participation universities, and career development interventions in particular, to address and integrate sociocultural context into their career services in order to expand students' perceptions of possible career options [1] and to increase students' ability to influence their social standing [19]. Universities need to develop employability-enhancing strategies that help students to understand whether and how they integrate their cultural factors and ethnic group expectations into their career decision-making [1].

This study proposes that coaching provides an opportunity for the widening participation universities to address the issues of students' lack of social capital and lack of professional role models [24][35][42][49]. We also believe that coaching (one-to-one, career coaching, group coaching) can help students to develop their full potential, regardless of background and wealth, through empowerment [25] and increased self-awareness and self-efficacy [18].

Hence, the following research questions guided this study:

RQ1. Is career coaching effective in increasing students' career decision self-efficacy and their employability efforts?

RQ2. What are students' self-efficacy and outcome expectation beliefs?

RQ3. What factors impact students' self-efficacy, outcome expectations and employability efforts?

\section{Theory}

Employability of students has become a very important strategic issue in Higher Education [13][14][33][50]. However, curricula designed to increase employability lack a consistent approach [49]. Moreover, employability models proposed in the literature [23][25][29] do not incorporate students' social and political context [44].

This study argues that students' employability efforts can be seen as a case of vocational behaviour and as such should be analyzed in the Social Cognitive Career Theory context.

\subsection{Conceptual Framework: Social Cognitive Career Theory}

Social Cognitive Career Theory (SCCT) is derived from Bandura's [4] work and it incorporates factors such as gender, ethnicity and cultural and gender role models and influences into its framework [47]. This approach, relatively new and used mainly in the educational and career context, aims to unify earlier career theories [30][41]. SCCT provided a conceptual framework for this study, with coaching as a learning tool and employability efforts added to the model in red font (see Figure 1 below). 


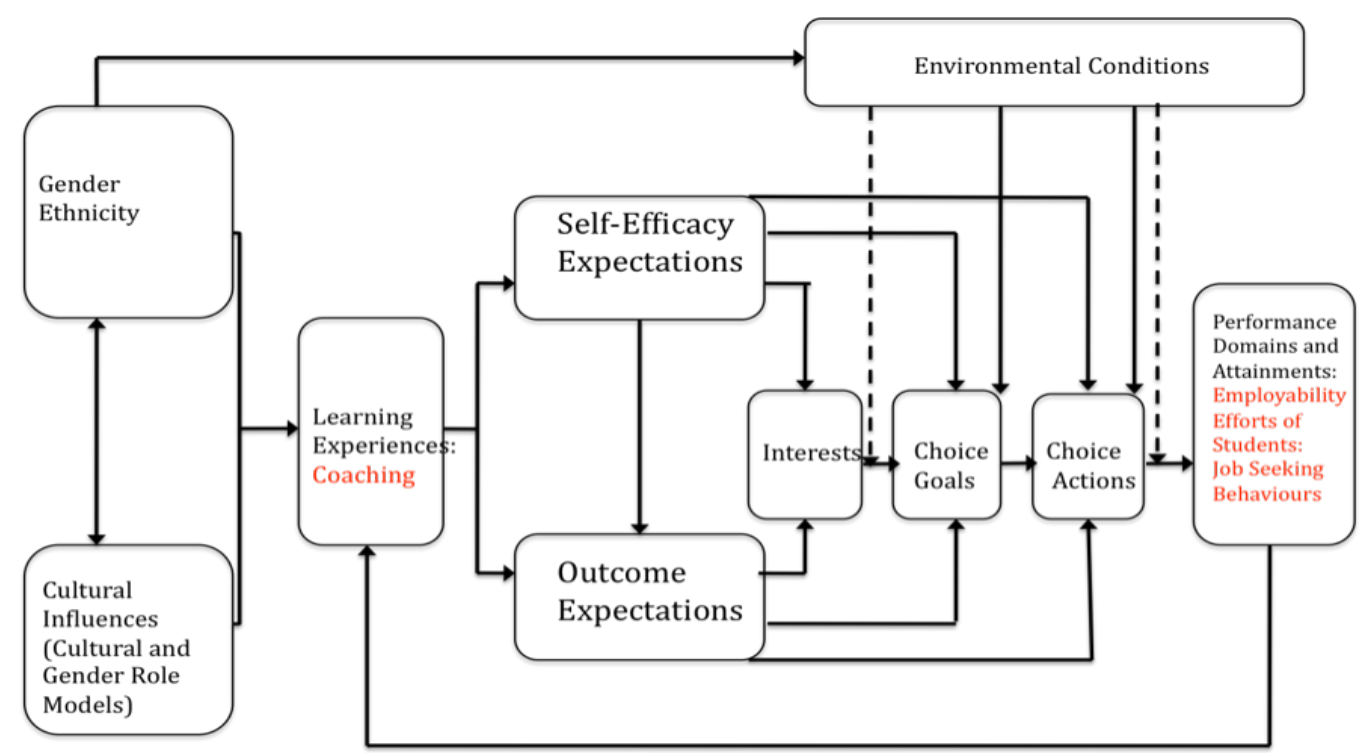

Figure 1: SCCT as an employability framework

A coaching intervention was proposed as a proxy for learning experiences in the adapted SCCT model. Coaching can be seen as a positive influence that helps individuals to align their behaviour with their career goals [38] and as an effective learning tool [16][28] that increases self-efficacy [27][42][51]. Employability efforts were considered to be performance domains and attainments in the model. Since employability focuses on development of soft skills it is difficult to propose employability measures that would fit all learners [31] and that are valid and reliable [6]. Hence, job search behaviours were chosen as a proxy for employability efforts in this study.

\subsection{Coaching Effectiveness}

Coaching effectiveness is usually measured via treating coaching as an intervention in experimental or quasi-experimental design [8][55] in which coaching effectiveness is measured against psychological scales and its effectiveness is captured via increase in the above scales [2][55]. This study used a common factors theory to investigate effectiveness of career coaching in increasing students' selfefficacy and their employability efforts. Common factors are conditions shared amongst different therapeutic approaches that lead to successful therapy outcomes [32], namely: extra-therapeutic factors (client and his environment); coaching relationship, expectancy and coaching techniques [37]. A common factor approach is central to coaching effectiveness [9] and is a useful way of testing the mechanism of change [22]. 


\section{Method}

\subsection{Research Design}

The study used a pre- and post-test quasi-experimental and longitudinal design. The experimental group received 6 career-coaching sessions over a period of six months from professionals working in corporate companies in London in the United Kingdom. The control group received no coaching. The qualitative part of this research was designed to explore changes in self-efficacy and job seeking behaviour as well as the impact of gender, ethnicity, perceived social support, socioeconomic status, cultural influences and gender role models on students' employability efforts.

\subsection{Sampling Strategy}

The participants consisted of Year 1, Year 2 and Year 3 undergraduate students attending a large widening participation university in the United Kingdom. The Time 1 sample consisted of 955 students. The Time 2 sample consisted of 245 students. At Time 3, at the qualitative stage, maximum variation sampling was used that was based on changes in students' self-efficacy levels. Forty students, 10 with the highest and 10 with the lowest increase in career self-efficacy in both groups were invited for the semi-structured one-to-one face-to-face 60 -minute interviews.

\subsection{Research Instruments}

Career decision self-efficacy was measured using a 25-item short form scale [39]. Students were asked to indicate how much confidence they had in accomplishing the tasks using a 5-point Likert scale. The items included "Make a plan of your goals for the next five years." (Cronbach's alpha $=.95$ ).

Vocational outcome expectations, a 12-item scale [36] measured students' outcome expectations. A 4-point Likert scale measured items such as: "My career planning will lead to a satisfying career for me $($ Cronbach's alpha $=.83)$.

Students' employability efforts were measured using a modified [3] 5-point Likert scale consisting of the 8-item preparatory job search behavior (PJSB) scale (Cronbach's alpha $=.93$ ), the 6-item active job search behavior scale (AJSB) (Cronbach's alpha $=.83$ ) and the 4-item job search intensity scale (JSI) $($ Cronbach's alpha $=.94)$.

The semi-structured interview schedule was based on research questions and research constructs derived from the common factors theory and from the SCCT.

\section{Findings and Discussion}

The qualitative data showed that students identified many benefits of career coaching, including improved resilience. Many students perceived their coach as a role model. This is consistent with other findings in the literature about the impact of role models [34]. However, the current study did not manage to capture quantitatively the effectiveness of coaching intervention. The Time 2 MANOVA comparison showed no differences between the both groups. The possible explanation for these findings 
might be that people overestimate their abilities at the baseline [28] leaving little room for change as a result of the intervention [5]. Some researchers recommend using a self-efficacy scale ranging from 0 to 100 [12].

The study found practical advice to be of importance to students. Similar backgrounds, age, gender or ethnicity, the same country of origin played also an important role in building effective coaching relationships. These findings are consistent with other studies [34] and with coaching literature [21]. Overall, students believed that they had as many career options as others as long as they put effort and motivation into it. However, students' positive self-efficacy beliefs were inhibited by students' negative self-perception of themselves. Most students reported having access to limited social capital.

The study also found ethnicity to moderate students' employability efforts. This finding was supported by qualitative interviews.

\section{Conclusion and Implications for Practice}

Coaching, as part of a universities' employability strategy, might be a way to address students' lack of social capital and their lack of role models. Creating opportunities for students to build social capital should become an important part of the universities' employability agenda. This might be achieved by providing role models with whom students can identify [52]. It is also important that career services use different strategies to reach out to ethnic minority students as these students tend to underuse them [20][26]. The effectiveness of career coaching can be also increased by allocating to immigrant students career coaches who are also immigrants and who are professionally successful [45].

There is a need for career development interventions to address and integrate students' sociocultural context into career services particularly for widening participation universities [1][24]. Career interventions should focus on overcoming ethnic and cultural stereotypes [17]. Training of career coaches should include self-efficacy enhancing strategies [53]. It is also important for ethnic minorities to be encouraged to identify and connect to support networks in their environment [15]. Finally, it is recommended that widening participation universities adapt an employability model that recognises socioeconomic, cultural and ethnic barriers students in order to support employability efforts of their students more effectively [24].

\section{Recommendations for Future Research}

The findings of the study can be further expanded by comparing this case study's results with a Russell Group university. It is also recommended that future studies explore how culture influences students' self-efficacy and outcome expectation beliefs.

\section{References}

[1] A.M. Gloria, and J.S. Hird, "Influences of ethnic and nonethnic variables on the career decisionmaking self-efficacy of college students", Career Development Quarterly, 48(2), 1999, pp.157-174. 
[2] A.M. Grant, L. Curtayne, and G. Burton, "Executive coaching enhances goal attainment, resilience and workplace well-being: a randomised controlled study", The Journal of Positive Psychology, 4(5), 2009, pp.396-407.

[3] A.M. Saks, and B.E. Ashforth, (1999) 'Effects of individual differences and job search behaviors on the employment status of recent university graduates", Journal of Vocational Behavior, 54(2), 1999, pp.335-349.

[4] Bandura, A., Social foundations of thought and action: A social cognitive theory, Prentice-Hall, Englewood Cliffs, NJ, 1985.

[5] Blades, R., Fauth, B. and Gibb, J., "Measuring Employability Skills: A rapid review to inform development of tools for project evaluation" NCB Research Centre, Online, 2012, Available from: http://www.partners4value.lt/wp-content/uploads/2015/10/Measuring-Employability-Skills.pdf (Accessed 25 April 2019).

[6] Deloitte, Employability: A review and analysis of the assessment/recognition processes that are used to accredit and otherwise measure the development of employability skills - both for individuals and for institutions, UK Commission for Employment and Skills, London, 2010.

[7] D. Chadha, and J. Toner, "Focusing in on employability: using content analysis to explore the employability discourse in UK and USA universities", International Journal of Educational Technology in Higher Education, 14(33), 2017.

[8] D. MacKie, "The effectiveness of strength-based executive coaching in enhancing full range leadership development: A controlled study", Consulting Psychology Journal: Theory and Research, 66(2), 2014, pp.118-137.

[9] E. de Haan, A. Duckworth., D. Birch, and C. Jones, "Executive coaching outcome research: The contribution of common factors such as relationship, personality match, and self-efficacy", Consulting Psychology Journal: Practice and Research, 65(1), 2013, pp.40-57.

[10] E. Ingleby, "It does more than it says on the tin! Problematising higher education in further education in England", Studies in Higher Education, 44(1), 2019, pp. 20-30.

[11] Faulkner, N., What is a University Education For?, pp.27-36, In. Bailey, M. and Freedman, D. (Eds), The Assault on Universities: A Manifesto for Resistance, Pluto Press, London, 2011.

[12] F. Pajares, J. Hartley, and G. Valiante, "Response format in writing self-efficacy assessment: Greater discrimination increases prediction", Measurement and Evaluation in Counseling and Development, 33(4), 2001, pp.214-221.

[13] Freedman, D., An Introduction to Education Reform and Resistance, pp.1-11, In. Bailey, M. and Freedman, D. (Eds.), The Assault on Universities: A Manifesto for Resistance, Pluto Press, London, 2011.

[14] F. Suleman, "The employability skills of higher education graduates: insights into conceptual frameworks and methodological options", High Education, 76, 2018, pp. 263-278. 
[15] G. Hackett, and A.M. Byars, "Social cognitive theory and the career development of African American women", Career Development Quarterly, 44(4), 1996, pp.322-341.

[16] Griffiths, K. 'Personal coaching: A model for effective learning”, Journal of Learning Design, $1(2), 2005$, pp.55-65.

[17] G.V. Gushue, and M.L. Whitson, "The relationship among support, ethnic identity, career decision self-efficacy, and outcome expectations in African American high school students", Journal of Career Development, 33(2), 2006, pp.19-28.

[18] J. Artess, T. Hooley, and R. Mellors-Bourne, "Employability: A review of the literature 2012 - 2016" Higher Education Academy (HEA), York,Online, 2017, Available from: http://hdl.handle.net/10545/621285 (Accessed 29 April 2019).

[19] J. Metheny, and E.H. McWhirter, "Contributions of social status and family support to college students' career decision-making self-efficacy and outcome expectations", Journal of Career Assessment, 21(3), 2013, pp.378 - 394.

[20] J.W. Falconer, and K.A. Hays, "Influential Factors Regarding the Career Development of African American College Students. A Focus Group Approach", Journal of Career Development, 32(3), 2006, pp.219-233.

[21] K. Gyllensten, and S. Palmer, "The coaching relationship: An interpretative phenomenological analysis", International Coaching Psychology Review, 2(2), 2007, pp.168-176.

[22] K.M. Laska, A.S. Gurman, and B.E. Wampold, "Expanding the lens of evidence-based practice in psychotherapy: A common factors perspective. Special Section: Common Factors", Psychotherapy, 51(4), 2014, pp.467-481.

[23] Knight, P., and Yorke, M. 'Employability through the curriculum'. Skills Plus Project, 2001.

[24] K. Tate, W. Caperton, D. Kaiser, N.T, Pruitt, H. White, and E. Hall, "An Exploration of FirstGeneration College Students' Career Development Beliefs and Experiences", Journal of Career Development, 2015, pp.1-17.

[25] Kumar, A., Personal, Academic and Career Development in Higher Education: SOARing to success, Routledge, New York, 2007.

[26] L. Andrewartha, and A. Harvey, "Employability and student equity in higher education: The role of university careers services", Australian Journal of Career Development, 26(2), 2017, pp.71-80.

[27] L. Baron, L. Morin, and D. Morin, "Executive coaching: The effect of working alliance discrepancy on the development of coachees' self-efficacy", Journal of Management Development, 30(9), 2011, pp.847-864.

[28] L. Cruz, and L. Rosemond, "Coaching academia: The integration of coaching, educational development, and the culture of higher education", Journal on Excellence in College Teaching, 28(4), 2017, pp.83-108. 
[29] L. Dacre Pool, and P. Sewell, "The Key to Employability. Developing a practical model of graduate employability", Education and Training, 49(4), 2007, pp.277- 289.

[30] Lent, R.W., Social Cognitive Career Theory, pp. 115-146, In Brown, S.D. and Lent, R.W. (Eds.), Career Development and Counseling: Putting Theory and Research to Work, (2 ${ }^{\text {nd }}$ ed.), John Wiley \& Sons, Inc., New Jersey, 2013.

[31] Lloyd, R. and F. O'Sullivan, Measuring Soft Outcomes and Distance Travelled; a Methodology for Developing a Guidance Document, Department for Work and Pensions, London, 2003.

[32] L.M. Grencavage, and J.C. Norcross, "Where Are the Commonalities Among the Therapeutic Common Factors?", Professional Psychology: Research and Practice, 21(5), 1990, pp.372 -378.

[33] L. Small, K. Shacklock, and T. Marchant, (2018), "Employability: a contemporary review for higher education stakeholders, Journal of Vocational Education \& Training, 70(1), 2018, pp.148-166.

[34] L.Y. Flores, E.M. Obasi, "Mentors' Influence on Mexican American Students' Career and Educational Development", Journal of Multicultural Counseling and Development, 33(3), 2005, pp.146-164.

[35] M. Craig, "The role of local networks in developing social capital and empowering young people: a case study", Curriculum Leadership Journal, 1, 1-16, Online, 2003, Available from: http://www.curriculum.edu.au/leader/the_role_of_local_networks_in_developing_social_ca,4640.htm 1?issueID=9691 (Accessed 25 April 2019).

[36] McWhirter, E. H., \& Metheny, J. (2009). Vocational Outcome Expectations-Revised. A revised measure of expectations associated with high school career planning. Unpublished measure.

[37] Miller, S., D. Barry, and M. Hubble, Escape from Babel, W.W. Northon and Company, New York, 1997.

[38] M. Shapiro, D. Grossman, S. Carter, K. Martin, P. Deyton, and D. Hammer, "Middle school girls and the "leaky pipeline" to leadership", Middle School Journal, 46(5), 2015, pp.3-13.

[39] N.E. Betz, K.L. Klein, and K.M. Taylor, "Evaluation of a short form of the Career DecisionMaking Self-Efficacy Scale", Journal of Career Assessment, 4(1), 1996, pp.47-57.

[40] Nixon, J., Re-Imagining the Public Good, pp.59-70, In. Bailey, M. and Freedman, D. (Eds), The Assault on Universities: A Manifesto for Resistance. Pluto Press, London, 2011.

[41] N. Kantamneni, K. Dharmalingam, G. Orley, and S.K. Kanagasingam, Cultural factors, perceived barriers, and Asian American career development: An application of social cognitive career theory. Journal of Career Assessment, 2017, pp.1-17.

[42] N. Lancer, and V. Eatough, 'One-to-one coaching as a catalyst for personal development: An Interpretative Phenomenological Analysis of coaching undergraduates at a UK university', International Coaching Psychology Review, 1(13), 2018, pp.72-88. 
[43] Patton, M. Q. Qualitative Research and Evaluation Methods. $4^{\text {th }}$ edn. Sage, Thousand Oaks, CA, 2015

[44] P. McCash, "We're all career researchers now: breaking open career education and DOTS", British Journal of Guidance and Counselling, 34(4), 2006, pp.430-49.

[45] P-W. W. Ma, and C.J. Yeh, "Individual and Familial Factors Influencing the Educational and Career Plans of Chinese Immigrant Youths", The Career Development Quarterly, 58(3), 2010, pp.230245.

[46] R.A. Giacalone, "Academic Rankings in Research Institutions: A Case of Skewed Min Sets and Professional Amnesia", Academy of Management Learning \& Education, 8, 2009, pp.122-126.

[47] R.W. Lent, D.S. Brown, and G.Hackett, "Toward a Unifying Social Cognitive Theory of Career and Academic Interest, Choice, and Performance", Journal of Vocational Behavior, 45(1), 1994, pp.79122.

[48] Salkind, N.J., Exploring Research, $9^{\text {th }}$ edn. Pearson Education, Inc., New Jersey, 2017.

[49] S. Hill, "Making connections: the role of social capital in the enhancement of employability of first generation business studies graduates", Widening Participation and Lifelong Learning, 13(2), 2011, pp. $33-50$.

[50] S. Minocha, D. Hristov, and M. Reynolds, 'From graduate employability to

employment: policy and practice in UK higher education', International Journal of Training and Development 21(3), 2017, pp.235-248.

[51] Sutton Trust, Sutton Trust Briefing Note: The Educational Backgrounds of the UKs Top Solicitors, Barristers and Judges, The Sutton Trust, London, June 2005.

[52] S.R. Ali, E.H. McWhirter, and K.M. Chronister, "Self-efficacy and vocational outcome expectations for adolescent of lower socioeconomic status: A pilot study", Journal of Career Assessment, 13(1), 2005, pp.40-58.

[53] Van Hoye, G., Job Search Behavior as a Multidimensional Construct: A Review of Different Job Search Behaviors and Sources, In U. C. Klehe \& E. A. J. van Hooft (Eds.), The Oxford Handbook of Job Loss and Job Search, Oxford University Press, New York, 2018.

[54] Walton, J.K., The Idea of the University, pp. 15-26, In. Bailey, M. and Freedman, D. (Eds), The Assault on Universities: A Manifesto for Resistance, Pluto Press, London, 2011.

[55] W.J.G. Evers, A. Brouwers, and W. Tomic, "A quasi-experimental study on management coaching effectiveness", Consulting Psychology Journal: Practice and Research, 58(3), 2006, pp.17482. 